ORIGINAL ARTICLE

\title{
Respiratory disease and cardiovascular morbidity
}

\author{
R-S Koskela, P Mutanen, J-A Sorsa, M Klockars
}

Occup Environ Med 2005;62:650-655. doi: 10.1136/oem.2004.017111

Background: Work related dust exposure is a risk factor for acute and chronic respiratory irritation and inflammation. Exposure to dust and cigarette smoke predisposes to exogenous viral and bacterial infections of the respiratory tract. Respiratory infection can also act as a risk factor in the development of atherosclerotic and coronary artery disease.

Aims: To investigate the association of dust exposure and respiratory diseases with ischaemic heart disease (IHD) and other cardiovascular diseases (CVDs).

Methods: The study comprised 6022 dust exposed (granite, foundry, cotton mill, iron foundry, metal product, and electrical) workers hired in 1940-76 and followed until the end of 1992. National mortality and morbidity registers and questionnaires were used. The statistical methods were person-year analysis and Cox regression.

See end of article for authors' affiliations

Results: Co-morbidity from cardiovascular and respiratory diseases ranged from $17 \%$ to $35 \%$. In at least $60 \%$ of the co-morbidity cases a respiratory disease preceded a cardiovascular disease. Chronic bronchitis, pneumonia, and upper respiratory track infections predicted IHD in granite workers (rate ratio $(\mathrm{RR})=1.9 ; 95 \% \mathrm{Cl} 1.38$ to 2.72 ), foundry workers $(2.1 ; 1.48$ to 2.93$)$, and iron foundry workers (1.7;

Correspondence to: Dr R-S Koskela, Finnish Institute of Occupational Health, Topeliuksenk. 41 a A, FIN-00250 Helsinki, Finland; riitta-sisko. koskela@Hl.fi 1.16 to 2.35). Dust exposure was not a significant predictor of IHD or other CVD in any group. Dust exposure was related to respiratory morbidity. Thus, some respiratory diseases appeared to act as intermediate variables in the association of dust exposure with IHD.

Conclusion: Dust exposure had only a small direct effect on IHD and other CVD. IHD morbidity was

Accepted 18 March 2005 associated with preceding respiratory morbidity. A chronic infectious respiratory tract disease appeared to play an independent role in the development of IHD.

W ork related dust exposure is a generally accepted risk factor for acute and chronic respiratory irritation and inflammation. Moreover, exposure to dust and cigarette smoke predisposes to exogenous viral and bacterial infections of the respiratory tract.

A number of risk factors have been established for coronary artery disease. Experimental and epidemiological studies have shown a positive correlation between coronary atherosclerosis and a variety of infectious agents of both viral and bacterial origin. ${ }^{1}$ Atherosclerosis can also be induced in animal models by microorganisms. ${ }^{2}{ }^{3}$ The atherosclerotic lesion represents specific cellular and molecular changes that are no different from the "classical" inflammatory response. ${ }^{14}$ The frequently observed correlation between the incidence of atherosclerosis and the presence of a variety of infectious microorganisms including herpes viruses (particularly cytomegalovirus), Helicobacter pylori, and Chlamydia pneumoniae has suggested an infectious aetiology of coronary artery disease. ${ }^{5-7}$

Besides the involvement of inflammation in "active" coronary artery disease, chronic systemic infection may accelerate the clinical course of atherosclerosis. ${ }^{8}$ Increased levels of antibodies to Chlamydia pneumoniae in coronary patients were reported in 1988. ${ }^{7}$ Symptoms of respiratory infection often precede myocardial infarction ${ }^{10}$ and symptoms of chronic bronchitis predict the risk of coronary disease independently of the known major cardiovascular risk factors. ${ }^{11}$ Respiratory infection may thus act as a synergistic risk factor together with the classical risk factors in the development of atherosclerotic and coronary artery disease.

The aim of our study was to investigate the association of respiratory diseases with ischaemic heart disease and other cardiovascular diseases and to assess the potential intermediate role played by respiratory diseases in the association of dust exposure with ischaemic heart disease.

\section{METHODS}

\section{Study subjects and data collection}

The study population comprised a sample of 6022 current and former workers from a total of 22000 members of six cohorts variously exposed to dust. A cohort of granite workers consisted of 1026 men hired in quarries and processing yards in 1940-71. ${ }^{12}{ }^{13}$ A cohort of foundry workers consisted of 931 men exposed for at least 4.2 years (hired in 1950-72 and still actively working in iron, steel, and non-ferrous foundries in 1972). ${ }^{14}{ }^{15}$ A cohort of cotton mill workers comprised 1065 women exposed to raw cotton dust for at least five years (hired in 1950-71). ${ }^{16}$ The three other cohorts were derived from the metal industry: 1000 iron foundry workers, 1000 metal product workers (manufacture of fabricated metal products, machinery and equipment), and 1000 electrical workers (production of electrical devices and of electrical machinery, apparatus, appliances, and supplies) hired in 1950-76 and living in 1976. (A total of 400 current and 400 former male workers with the longest duration of employment and 200 with the shortest duration of employment were selected in each branch.) All cohorts were followed until the end of 1992.

The studies on these cohorts were based on an agreement with labour market organisations, and the research protocols were approved by the Research Committee of the Finnish Institute of Occupational Health. Register based data were collected with the consent of the legal authorities. Participation in the questionnaires was voluntary and was based on written information given previously to the respondents.

Abbreviations: $\mathrm{Cl}$, confidence interval; $\mathrm{CRP}, \mathrm{C}$ reactive protein; $\mathrm{CVD}$, cardiovascular diseases; ICD, International Classification of Diseases; $I H D$, ischaemic heart disease; $R R$, rate ratio 


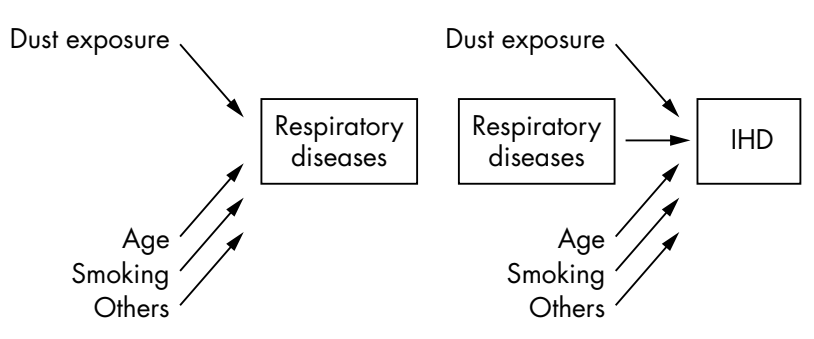

Figure 1 Respiratory diseases as intermediate variables between dust exposure and ischaemic heart disease (IHD).

The vital statuses and addresses of the workers were traced through the Population Information System. Causes of death in 1940-92 were obtained from Statistics Finland. Causes of disability in 1969-92 were available from the Social Insurance Institution. The whole range of respiratory and cardiovascular diseases was available from the death and disability registers. Data on medicines for which special compensation $(80-100 \%)$ is granted under the National Sickness Insurance Act were available for 1969-92 from the Social Insurance Institution. The cardiovascular diseases eligible for specially compensated medicines are coronary heart disease, cardiac insufficiency, cardiac arrhythmia, and hypertension. The only respiratory disease eligible for special compensation is bronchial asthma. Data on occupational history, smoking, angina pectoris, chronic bronchitis, and respiratory diseases diagnosed by a doctor were collected via questionnaire. The questionnaire was administered to the granite workers in 1986 (response rate 81\%), to the foundry workers in $1993(79 \%)$, to the cotton mill workers in 1985 $(73 \%)$, to the iron foundry workers in $1980(79 \%)$, to the metal product workers in $1980(80 \%)$, and to the electrical workers in 1980 (75\%).

The diseases were coded according to the eighth revision of the ICD. ${ }^{18}$ Each diagnosed disease entered in the registers or marked with the year of diagnosis in the questionnaires was included. Mild or severe angina pectoris ${ }^{19}$ and chronic bronchitis $^{20-23}$ reported in the standardised questionnaire were included as diagnosed diseases. All diseases obtained in the above manner were sorted by year of diagnosis to establish the earliest time point of each diagnosis for each cohort member and to determine the order of subsequent diseases.

\section{Statistical analyses}

Morbidity from cardiovascular and respiratory diseases was assessed by person-year analysis ${ }^{24}$ and Cox regression. ${ }^{25}$ The SAS system (version 8.1; SAS Institute, Inc., Cary, North Carolina) was used for statistical analysis.

In multivariate analyses the respiratory diseases were classified into five categories: chronic bronchitis (ICD 490.99-491.09), emphysema and asthma (ICD 492.01493.09), pneumoconiosis (ICD 515.00-516.20), pneumonia (ICD 480.99-486.09), and other respiratory diseases (ICD 460.00-474.99, 500.99-514.99, and 517.01-519.98). In a separate analysis, these disease categories were used to predict the first subsequent occurrence of ischaemic heart disease (IHD) (ICD 410.00-414.99) and other cardiovascular diseases (CVDs) (ICD 390.97-458.99, excluding 410.00414.99). The other variables in the models were age at entry to the work under study, lifelong smoking habits (smoker, ex-smoker, non-smoker), and dust exposure (defined as exposure years multiplied by dust concentration $10 \mathrm{mg}-\mathrm{y} / \mathrm{m}^{3}$ or dust category, or as exposure years only). Dust exposure was treated in Cox regression as a time varying variable, and was calculated to estimate cumulative exposure at the time of the IHD event. The respiratory disease variables were also treated as time varying to establish whether or not the person had a certain type of respiratory disease before the time of the IHD event. In addition, carbon monoxide exposure was used as an explanatory variable for foundry workers. The effects of hypertension and congestive heart failure on IHD were controlled for as explanatory factors in the final analyses.

Respiratory diseases can be causal factors of IHD. Respiratory diseases, in turn, may be caused by dust exposure, smoking, and age, and are thus intermediate factors in the course of IHD (fig 1). Respiratory diseases as possible intermediate variables were studied by Cox regression analysis in two stages. First, the predictors of IHD and other CVDs were studied, with respiratory diseases and dust exposure as explanatory variables. Second, respiratory diseases were studied as response variables, with dust exposure as an explanatory variable. Rate ratios (RR) were used as the effect measures of the explanatory variables.

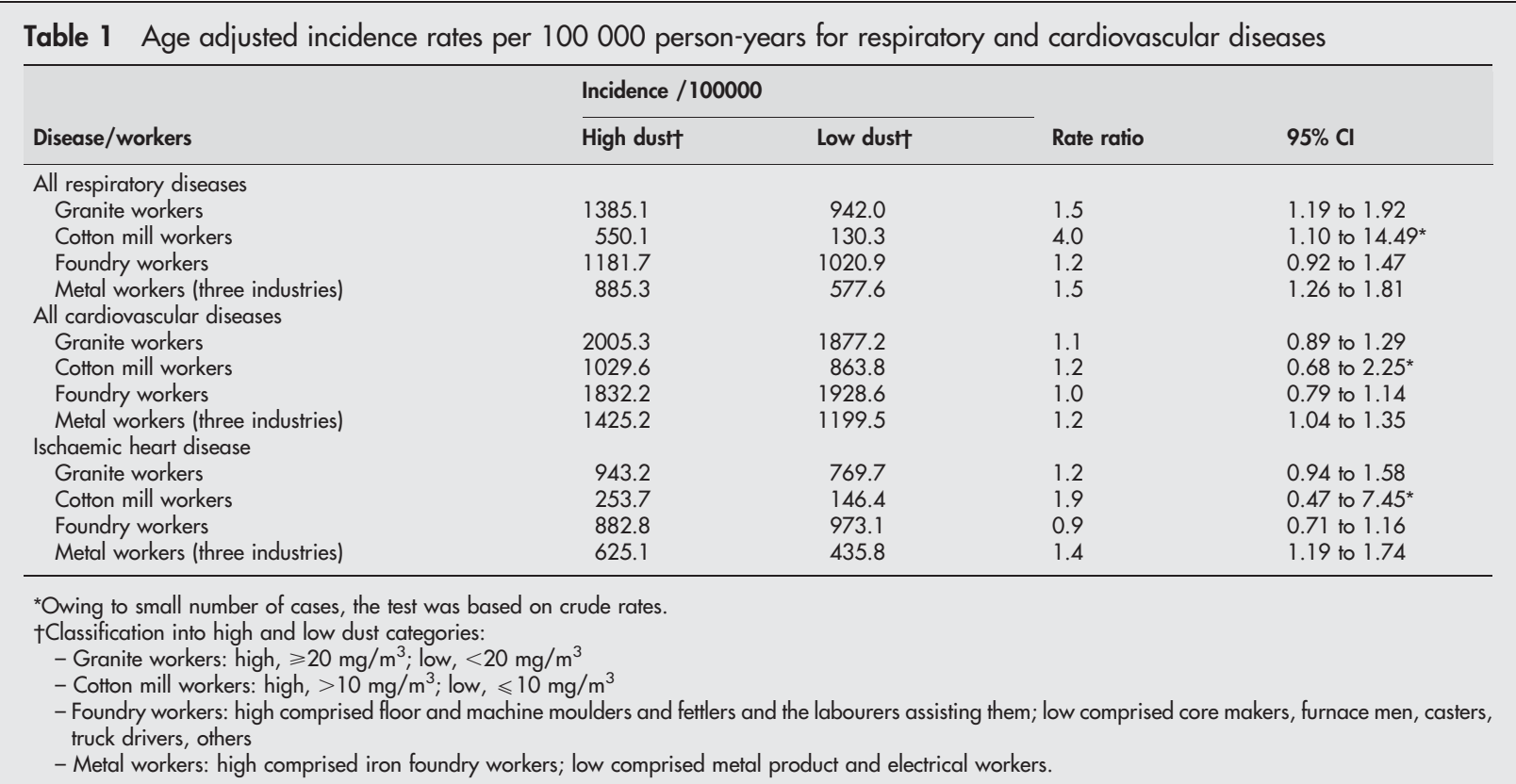


The potential violation of proportional hazard assumption was studied for the variables of age at entry, smoking, and dust exposure. The proportional hazard assumption was not fulfilled for the age at entry variable in any of the study groups. Consequently, all the results are based on the models including the interaction term between age and follow up time.

\section{RESULTS}

Person-year analyses of cardiovascular and respiratory diseases by dust exposure (table 1) showed that, in almost all study groups, morbidity from respiratory diseases was higher among workers with high exposure than among those with low exposure. Systematic, though mostly slight, differences were observed for all cardiovascular diseases and for IHD separately.

Co-morbidity from cardiovascular and respiratory diseases ranged from $17 \%$ to $35 \%$ in the study groups. In each study group, a respiratory disease preceded a cardiovascular disease in at least $60 \%$ of the co-morbidity cases. Respiratory diseases as possible predictors of CVDs were studied by multivariate analyses.

First, in the study of cardiovascular diseases, respiratory diseases and dust exposure were used as explanatory variables (table 2). For IHD, chronic bronchitis was a significant predictor for three occupational groups (granite workers, $\mathrm{RR}=2.2,95 \%$ CI 1.52 to 3.27 ; foundry workers, $\mathrm{RR}=2.3$, 95\% CI 1.59 to 3.40; and iron foundry workers, $\mathrm{RR}=2.0$, 95\% CI 1.41 to 2.96 ). Pneumonia showed a rate ratio of 1.4 (95\% CI 0.86 to 2.27 ) among granite workers and of 2.0 (95\% CI 0.93 to 4.27) among cotton mill workers. For other respiratory diseases (upper respiratory infections), the rate ratio among granite workers was 1.7 (95\% CI 0.95 to 3.14). Emphysema and asthma did not prove to be predictors of IHD in any study group except electrical workers; among cotton mill workers the rate ratio was rather high $(\mathrm{RR}=2.0$; 95\% CI 0.91 to 4.57 ). Pneumoconiosis had predictive value for cotton mill workers and iron foundry workers. Adding carbon monoxide exposure into the model for foundry workers did not change the results for respiratory diseases; it did, however, change the significance of dust exposure, with which it correlated (data not shown). For the other CVDs (CVD excluding IHD), pneumonia had predictive value for three study groups (granite workers, RR $=2.0,95 \%$ CI 1.40 to 2.83; iron foundry workers, $\mathrm{RR}=1.6,95 \% \mathrm{CI} 1.10$ to 2.44 ; and electrical workers, $\mathrm{RR}=2.0,95 \%$ CI 0.99 to 3.95), whereas chronic bronchitis, emphysema, and asthma, as well as pneumoconiosis had predictive value for granite workers only. Chronic bronchitis was also a significant predictor for foundry workers.

Dust exposure was a weak predictor of IHD or of other CVDs in all the models presented here. Age and smoking had a high predictive value for IHD in each model (data not shown), whereas smoking did not predict other CVDs in any of the models.

Second, respiratory diseases were studied as response variables. The effect of dust exposure on each type of respiratory disease is presented in table 3 . The effect of a particular respiratory disease on ischaemic heart disease is presented simultaneously (table 3 ).

Dust exposure predicted chronic bronchitis among granite workers. Thus, dust exposure was associated with chronic bronchitis, and, further, chronic bronchitis was associated with IHD among granite workers. Dust exposure did not predict emphysema or asthma in any of the study groups; the only group in which respiratory diseases predicted IHD was that of electrical workers. Dust exposure predicted pneumoconiosis among granite workers. The results for pneumonia showed that dust exposure did not predict pneumonia in any

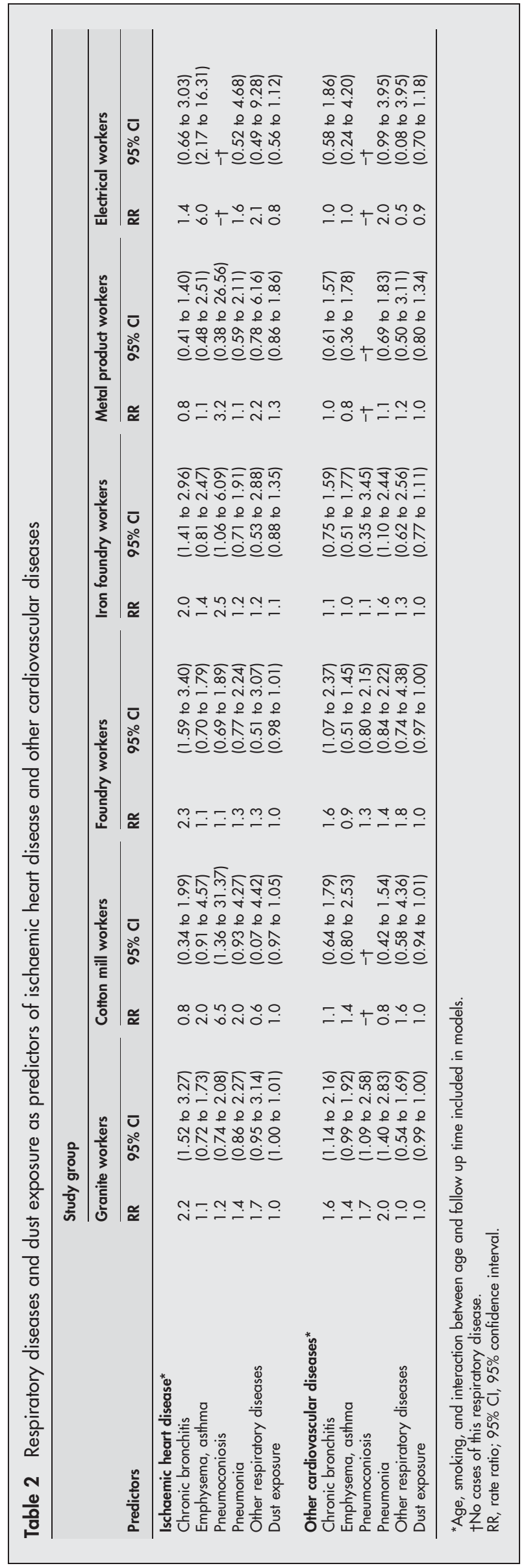




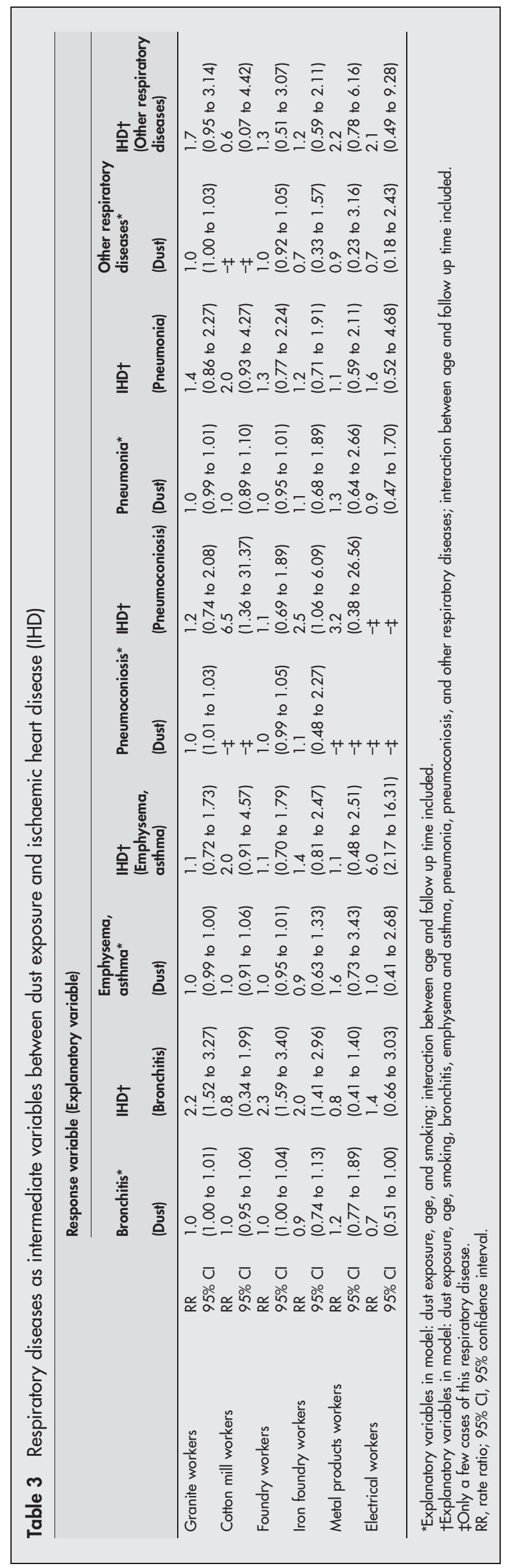

of the study groups. Dust exposure was associated with other respiratory diseases (mainly upper respiratory infections) among granite workers and, furthermore, other respiratory diseases showed a slight association with IHD; similar associations were not found for the other study groups.

Third, IHD was predicted with models that treated respiratory diseases as explanatory variables and included hypertension and congestive heart failure. Hypertension and congestive heart failure did not change the statistical significance of the five respiratory disease categories or other variables in the models. The rate ratio for hypertension ranged from 1.4 (95\% CI 1.00 to 1.97 ) to 2.4 (95\% CI 1.60 to 3.67 ) in all the study groups; for congestive heart failure, the rate ratio ranged from 1.3 (95\% CI 0.42 to 3.90 ) to 2.8 ( $95 \%$ CI 1.33 to 6.05 ) in all the study groups except those of electrical workers and foundry workers.

Table 4 represents the final model, in which respiratory diseases were divided into predominantly infectious (chronic bronchitis, pneumonia, and upper respiratory infections) and non-infectious (asthma, emphysema, and pneumoconiosis) diseases. Infectious respiratory diseases predicted IHD in the study groups of granite workers, foundry workers, and iron foundry workers-that is, groups with high dust exposure, whereas chronic non-infectious respiratory diseases clearly predicted IHD only among electrical workers, a group with low exposure to dust.

\section{DISCUSSION}

In our study, IHD morbidity was associated with preceding respiratory morbidity. The direct independent effect of dust exposure on IHD and other CVDs was small. Dust exposure was related to respiratory morbidity. Thus, some respiratory diseases seemed to act as intermediate variables in the association of dust exposure with IHD. Infectious respiratory diseases predicted IHD in more study groups than did chronic non-infectious respiratory diseases.

Epidemiological observations suggest that particulate air pollution is associated with cardiovascular effects. ${ }^{26-28}$ It has further been shown that inhaled ultrafine particles diffuse rapidly into the systemic circulation, and may thus be of relevance for cardiovascular morbidity and mortality related to ambient particle pollution..$^{29}$ There are plausible biological mechanisms by which ambient particles may lead to cardiac effects. Once deposited in the alveoli, inhaled particles may lead to the activation of inflammatory mediators, including cytokine production. In addition, changes in blood viscosity and effects on heart rate (autonomic function) may interfere with cardiac function. ${ }^{30-32}$ Urban air pollution may also provoke alveolar inflammation, with release of mediators capable of increasing blood coagulability in susceptible persons. ${ }^{33}$ In more advanced cases of dust induced respiratory disease, for example, in pneumoconiosis, pulmonary fibrosis may cause pulmonary heart disease.

The small effect of dust exposure on IHD and other CVDs noted here may be due partly to the methods we used. Dust exposure variables were strongly correlated with years since entry (time scale in the Cox regression model) and so were inefficient to predict the response event (IHD, other CVDs). The long exposure periods for most of the workers in each study group also cause homogeneity in the exposure variable and thus reduce its statistical significance, especially among worker groups with minimum periods of exposure (cotton mill and foundry workers). Due to the small variation in dust exposure, it is difficult to show differences in exposure between persons with and without IHD. Also the type of exposure was similar for the persons with and without IHD, because these persons were derived from the same cohort. All the above mentioned facts resulted rate ratios of about one. In addition, the model included five explanatory respiratory 
Table 4 Predicting ischaemic heart disease with infectious and non-infectious respiratory diseases

\begin{tabular}{|c|c|c|c|c|}
\hline \multirow[b]{2}{*}{ Workers } & \multicolumn{2}{|c|}{ Infectious respiratory diseases* } & \multicolumn{2}{|c|}{ Non-infectious respiratory diseases } \\
\hline & RR & $95 \% \mathrm{Cl}$ & $\mathbf{R R}$ & $95 \% \mathrm{Cl}$ \\
\hline Granite workers & 1.9 & (1.38 to 2.72$)$ & 1.1 & (0.77 to 1.67$)$ \\
\hline Cotton mill workers & 1.1 & $(0.59$ to 2.12$)$ & 1.9 & $(0.87$ to 4.00$)$ \\
\hline Foundry workers & 2.1 & (1.48 to 2.93 ) & 1.2 & (0.85 to 1.83$)$ \\
\hline Iron foundry workers & 1.7 & (1.16 to 2.35$)$ & 1.6 & $(0.98$ to 2.70$)$ \\
\hline Metal product workers & 1.0 & $(0.61$ to 1.61$)$ & 1.0 & $(0.45$ to 2.20$)$ \\
\hline Electrical workers & 1.7 & (0.91 to 3.37$)$ & 5.4 & (1.98 to 14.87$)$ \\
\hline
\end{tabular}

Other explanatory variables in the model were age, smoking, dust exposure, hypertension, and congestive heart failure.

${ }^{*}$ Chronic bronchitis, pneumonia, and upper respiratory infections.

†Bronchial asthma, emphysema, and pneumoconiosis.

$\mathrm{RR}$, rate ratio; $95 \% \mathrm{Cl}, 95 \%$ confidence interval.

variables, each reducing the effect of dust. Further, since smoking was significant it also reduced the effect of dust exposure. Moreover, health selection of persons with juvenile asthma, emphysema, or chronic bronchitis to jobs with low dust exposure (electrical work $)^{17}$ resulted in high rates of these diseases in occupations with low dust exposure, thus reducing the differences between the disease rates for low dust and high dust occupations.

Confounding by other occupational exposures was not probable. The granite workers were employed outdoors and were exposed to relatively pure silica. Only 3\% had obvious confounding exposure to other dusts or chemicals. ${ }^{13}$ The cotton mill workers were exposed to raw cotton dust over an average of 28 years. During their total occupational history only $6.5 \%$ of the workers were exposed to other dusts or chemicals. ${ }^{16}$ The workers in iron, steel, and non-ferrous foundries were exposed to sand dust. Total exposure to dust, including quartz dust, was highest in iron foundry workers and among floor moulders, machine moulders, and fettlers. ${ }^{34}$ The follow up of foundry workers until 1987 controlled for potential confounding exposure to polycyclic aromatic hydrocarbons and heat but found no dose-response correlation between exposure and CVDs. ${ }^{15} 35$ The effect of carbon monoxide was controlled for in the analyses conducted for the present study. The same potential confounding exposures as in the foundry cohort were found in the cohort of iron foundry workers. ${ }^{17}$ In the cohort of metal product workers, only a relatively low number of workers were exposed to potential confounding exposures: $10 \%$ were welders exposed to welding fumes, and $4 \%$ were painters, metal platers, and coaters exposed to solvents. ${ }^{17}$ Among the electrical workers, relevant confounding exposure to solvents, colophony, or resins was shown for soldering workers $(0.5 \%)$, exposure to solvents for metal platers and coaters ( $1.2 \%)$, and exposure to welding fumes for welders $(1.3 \%) .{ }^{17}$

In our study, respiratory morbidity (chronic bronchitis, pneumoconiosis) was associated with dust exposure, and IHD morbidity was associated with preceding respiratory morbidity. Infectious respiratory diseases-that is, chronic bronchitis, pneumonia, and upper respiratory infections, predicted IHD in more study groups than did chronic noninfectious respiratory diseases (asthma, emphysema, and pneumoconiosis).

Experimental and epidemiological studies have shown a positive correlation between coronary atherosclerosis and a variety of infectious agents of both viral and bacterial origin, and the cellular and molecular responses of atherosclerotic lesions resemble the "classical" inflammatory response. ${ }^{14}$ An association between atherosclerosis and the presence of certain infectious microorganisms has been reported for herpes viruses (particularly cytomegalovirus), Helicobacter pylori, and Chlamydia pneumoniae..$^{5-7}$ Dust and cigarette smoke exposure may also predispose to viral and bacterial infections of the respiratory tract.

Local or systemic low grade infections have been suggested as inducers of inflammatory reactions in atherosclerotic lesions, ${ }^{36}$ and chronic systemic infection may accelerate the clinical course of atherosclerosis. ${ }^{37}$ Among chronic infections, chronic bronchitis caused by inhalation of industrial dusts is associated with ischaemic heart disease. ${ }^{11}$ Respiratory infection may thus act as a synergistic risk factor together with classical risk factors in the development of atherosclerotic disease. Other potential pathophysiological links between respiratory infection(s) and coronary artery disease include direct arterial wall damage, the effect on blood lipids, ${ }^{38}$ and the production of acute phase reactants, for example, fibrinogen and $\mathrm{C}$ reactive protein (CRP). It has been shown that the baseline values of acute phase reactants, CRP included, are associated with the risk of coronary heart disease, ${ }^{39}$ chronic infections that cause a rise in circulating levels of CRP also yield a higher risk of CVD.

Respiratory diseases are associated with local and systemic inflammatory activity of different intensities. Patients with chronic bronchitis are more susceptible to bacterial bronchial infections than to infections at the emphysema or asthma ends of the spectrum. ${ }^{40}$ Bacterial infections are the main culprit in acute flares of the disease..$^{41}{ }^{42}$ Respiratory inflammatory diseases are associated with increased levels of acute phase reactants, including CRP levels. Despite a lack of diagnostic specificity, CRP levels reflect the presence and intensity of an inflammatory process. ${ }^{43}{ }^{44}$ Even considering the co-morbidity of different respiratory diseases, inflammatory activity is generally agreed to be more intense in pneumonia, exacerbated chronic bronchitis, and acute upper respiratory infections than in bronchial asthma and emphysema. The different humoral, cellular, and immunological responses and mediators in these diseases may explain the different associations with and development of IHD.

In conclusion, our study found that dust exposure had only a small direct effect on IHD and other CVDs. IHD morbidity was associated with preceding respiratory morbidity, and respiratory morbidity, in turn, was associated with dust exposure. Infectious respiratory diseases (chronic bronchitis, pneumonia, and upper respiratory infections) appeared to play an independent role in the development of IHD. Thus, efforts to prevent IHD should include the prevention of respiratory diseases and the control of dust exposure.

\section{ACKNOWLEDGEMENTS}

We express our sincerest thanks to Riitta Lukinmaa for her help in coding and handling the data. We also thank the Social Insurance Institution for the data on specially compensated medication and 
disability pensions, Statistics Finland for the data on causes of death, and the Population Register Center for data on vital statuses and addresses.

\section{Authors' affiliations}

R-S Koskela, P Mutanen, J-A Sorsa, Finnish Institute of Occupational Health, Topeliuksenk. 41 a A, FIN-00250 Helsinki, Finland

M Klockars, Department of Public Health, University of Helsinki, Finland

Competing interests: none declared

\section{REFERENCES}

1 Ross R. Mechanisms of disease: atherosclerosis - an inflammatory disease. N Engl J Med 1999;340:115-26.

2 Muhlstein JB, Andersson JL, Hammond EH, et al. Infection with Chlamydia pneumoniae accelerates the development of atherosclerosis and treatment with azithromycin prevents it in a rabbit model. Circulation 1998;97:633-6.

3 Nieto FJ. Infections and atherosclerosis: new clues from an old hypothesis. Am J Epidemiol 1998; 148:937-48.

4 Weissberg PL. Atherogenesis: current understanding of the causes of atheroma. Heart 2000;83:247-52.

5 Libby $\mathbf{P}$, Egan D, Skarlatos S. Roles of infectious agents in atherosclerosis and restenosis: an assessment of the evidence and need for future research. Circulation 1997;96:4095-103.

6 Hendrix MG, Salimans MM, van Boven CP, et al. High prevalence of latently present cytomegalovirus in arterial walls of patients suffering from grade III atherosclerosis. Am J Pathol 1990;136:23-8.

7 Saikku P, Leinonen M, Mattila K, et al. Serological evidence of an association of a novel chlamydia, TWAR, with chronic coronary heart disease and acute myocardial infarction. Lancet 1988;1I:983-5.

8 Libby P, Ridker PM, Maseri A. Inflammation and atherosclerosis. Circulation 2002; 105: 1135-43

9 Spodick DH, Flessas AP, Johnsson MM. Association of acute respiratory symptoms with onset of acute myocardial infarction: prospective investigation of 150 consecutive patients and matched control patients. Am J Cardiol 1984;53:481-2

10 Mattila KJ. Viral and bacterial infections in acute myocardial infarction. $J$ Intern Med 1989:225:293-6.

11 Jousilahti P, Vartiainen E, Tuomilehto J, et al. Symptoms of chronic bronchitis and the risk of coronary disease. Lancet 1996;348:567-72.

12 Koskela R-S, Klockars M, Järvinen E, et al. Mortality and disability among granite workers. Scand J Work Environ Health 1987;13:18-25.

13 Koskela R-S. Association of silica dust exposure with lung cancer and other diseases [dissertation]. University of Tampere, Tampere, 1995 (Acta Universitatis Tamperensis, ser A, vol. 460)

14 Koskela R-S, Hernberg S, Kärävä R, et al. A mortality study of foundry workers. Scand J Work Environ Health 1976;2(suppl 1):73-89.

15 Koskela R-S, Mutanen P, Sorsa J-A, et al. Factors predictive of ischemic heart disease mortality in foundry workers exposed to carbon monoxide. Am J Epidemiol 2000;152:628-32.

16 Koskela R-S, Klockars M, Järvinen E. Mortality and disability among cotton mill workers. Br J Ind Med 1990:47:384-91.

17 Koskela R-S. Mortality, morbidity and health selection among metal workers. Scand J Work Environ Health 1997;27(suppl 2): 1-80.

18 National Board of Health. Tauti- ja kuolinsyyluokitus [The WHO international statistical classification of diseases, injuries and causes of death]. Helsinki, Finland: National Board of Health, 1969.

19 Rose GA, Blackburn H. Cardiovascular survey methods. Geneva: World Health Organization, 1968.
20 Huhti E. Prevalence of respiratory symptoms, chronic bronchitis and pulmonary emphysema in a Finnish rural population. Acta Tuberc Scand 1965;61:(suppl LXI).

21 Medical Research Council's Committee on the Aetiology of Chronic Bronchitis. Standardized questionnaires on respiratory symptoms. BMJ 1960;2:1665.

22 Medical Research Council's Committee on the Aetiology of Chronic Bronchitis. Instructions for the use of the questionnaire on respiratory symptoms. London: British Research Council, 1960

23 Medical Research Council's Committee on the Aetiology of Chronic Bronchitis. Definition and classification of chronic bronchitis. Lancet 1965;1:775-9.

24 Breslow NE, Day NE, Heseltine E, eds. Statistical methods in cancer research. The design and analysis of cohort studies. Vol. II. IARC Scientific Publications no. 82. Lyon: International Agency for Research on Cancer, 1987.

25 Cox DR. Regression models and life tables (with discussion). J R Soc Stat B 1972;34:187-220.

26 Peters A, Döring A, Wichmann $\mathrm{HE}$, et al. Increased plasma viscosity during air pollution episode: a link to mortality? Lancet 1997;349:1582-7.

27 Peters A, Dockery DW, Muller JE, et al. Increased particulate air pollution and the triggering of myocardial infarction. Circulation 2001;103:2810-15.

28 Samet JM, Dominici F, Curriero FC, et al. Fine particulate air pollution and mortality in 20 U.S. cities, 1987-1994. N Engl J Med 2000;343:1742-9.

29 Nemmar DVM, Hoet P, Vanquickeborne B, et al. Passage of inhaled particles into the blood circulation in humans. Circulation 2002;105:411-14.

30 Pope CA III, Verrier RL, Lovett EG, et al. Heart rate variability associated with particulate air pollution. Am Heart J 1999;138:890-9.

31 Finkelstein JN, Johnston CJ, Barrett $\mathrm{T}$, et al. Particulate-cell interactions and pulmonary cytokine expression. Environ Health Perspect 1997; 105(suppl 5): 1179-82

32 Driscoll KE, Carter JM, Hassenbein DG, et al. Cytokines and particle-induced inflammatory cell recruitment. Environ Health Perspect 1997; 105(suppl 5):1159-64

33 Seaton A, MacNee W, Donaldson K, et al. Particulate air pollution and acute health effects. Lancet 1995;345:176-8.

34 Kärävä R, Hernberg S, Koskela R-S, et al. Prevalence of pneumoconiosis and chronic bronchitis in foundry workers. Scand J Work Environ Health 1976;2(suppl 1):64-72.

35 Koskela R-S. Cardiovascular diseases among foundry workers exposed to carbon monoxide. Scand J Work Environ Health 1994;20:286-93.

36 Kiechl S, Egger G, Mayr M, et al. Chronic infections and the risk of carotid atherosclerosis. Prospective results from a large population study. Circulation $2001 ; 103: 1064-70$

37 Keaney JF, Vita JA. The value of inflammation for predicting unstable angina. N Engl J Med 2002;347:55-7.

38 Laurila A, Bloigu A, Näyhä S, et al. Chronic Chlamydia pneumoniae infection is associated with a serum lipid profile known to be a risk factor for atherosclerosis. Arteriosclerosis Thrombosis Vasc Biol 1997; 17:2910-13.

39 Danesh J, Whincup P, Walker M, et al. Low grade inflammation and coronary heart disease: prospective study and updated meta-analyses. $B M$ 2000;321:199-204.

40 Wilson R. Evidence of bacterial infection in acute exacerbations of chronic bronchitis. Semin Respir Infect 2000;15:208-15.

41 Niroumand M, Grossman RF. Airway infection. Infect Dis Clin North Am 1998;12:671-88.

42 Read RC. Infection in acute exacerbations of chronic bronchitis: a clinical perspective. Respir Med 1999;93:845-50.

43 Ridker PM, Cushman M, Stamfer MJ, et al. Inflammation, aspirin, and the risk of cardiovascular disease in apparently healthy men. N Engl J Med 1997:336:973-9.

44 Ridker PM, Hennekens $\mathrm{CH}$, Buring JE, et al. C-reactive protein and other markers of inflammation in the prediction of cardiovascular disease in women. N Engl J Med 2000;342:836-43. 